\title{
Evaluation of the influence of fluoroquinolone chemical structure on stability: forced degradation and in silico studies
}

\author{
André Valle de Bairros ${ }^{1,2,3}$, Danillo Baptista Pereira', Everson Willian Fialho Cordeiro', \\ Clésio Soldateli Paim ${ }^{1,2}$, Fabiana Ernestina Barcellos da Silva ${ }^{1,2}$, Marcelo Donadel Malesuik ${ }^{1,2}$, \\ Fávero Reisdorfer Paula ${ }^{1,2 *}$
}

\author{
${ }^{1}$ Laboratory of Development and Quality Control in Drugs, Federal University of Pampa (UNIPAMPA), \\ Uruguaiana-RS, Brazil, ${ }^{2}$ Pharmaceutical Sciences Post Graduate Program, Federal University of Pampa (UNIPAMPA), \\ Uruguaiana-RS, Brazil, ${ }^{3}$ Department of Clinical and Toxicological Analysis, Federal University of Santa Maria (UFSM), \\ Santa Maria-RS, Brazil
}

\begin{abstract}
Fluoroquinolones are a known antibacterial class commonly used around the world. These compounds present relative stability and they may show some adverse effects according their distinct chemical structures. The chemical hydrolysis of five fluoroquinolones was studied using alkaline and photolytic degradation aiming to observe the differences in molecular reactivity. DFT/B3LYP-6.31G* was used to assist with understanding the chemical structure degradation. Gemifloxacin underwent degradation in alkaline medium. Gemifloxacin and danofloxacin showed more degradation perceptual indices in comparison with ciprofloxacin, enrofloxacin and norfloxacin in photolytic conditions. Some structural features were observed which may influence degradation, such as the presence of five member rings attached to the quinolone ring and the electrostatic positive charges, showed in maps of potential electrostatic charges. These measurements may be used in the design of effective and more stable fluoroquinolones as well as the investigation of degradation products from stress stability assays.
\end{abstract}

Keywords: Fluoroquinolones/evaluation. Forced degradation studies. Molecular modeling.

\section{INTRODUCTION}

Quinolones are a group of synthetic broad spectrum antibacterial drugs commonly used throughout the world. Nalidixic acid was the first compound introduced for therapeutics in 1962 for the treatment of urinary tract infections (Andersson, MacGowan, 2003; Petri, 2005). Different chemical changes to the basic structure of quinolones have been made over the years, aiming to improve the spectrum and antimicrobial activity and to minimize bacterial resistance. Currently, there are four generations of quinolones available for clinical use (Andersson, MacGowan, 2003; Petri, 2005), the main quinolones have a fluoro moiety attached to position 6

\footnotetext{
*Correspondence: F. R. Paula. Laboratório de Desenvolvimento e Controle de Qualidade de Fármacos e Medicamentos, Universidade Federal do Pampa (UNIPAMPA), Campus Uruguaiana, 97500-970 - BR 472 Km 592, Uruguaiana, RS, Brasil. Fax: 555534141484 Tel: 55553413 4321. E-mail: faveropaula@unipampa.edu.br
}

of the fused ring. The basic chemical structure of fluoroquinolones is shown in Figure 1.<smiles>O=C(O)c1c[nH]c2ccc(F)cc2c1=O</smiles>

FIGURE 1 - Basic chemical structure of fluoroquinolones.

The stability of drugs is a critical point of quality control and pharmacology for therapeutic agents, since a non-stable or reactive molecule may influence its structure, efficacy and safety. Stability tests, known as forced degradation studies, are important tools used to detect, quantify and identify the generation of degradation products (Alsante et al.; 2007; Singh et al., 2013). Forced degradation tests are applied by the pharmaceutical industry, usually under extreme conditions ( $\mathrm{ICH}, 2003$; 
Klick, 2005; ICH, 2006a; ICH, 2006b; Silva et al., 2009; Brasil, 2013), such as submitting the drug to acid, alkaline and oxidative media, high temperatures, and also to photolytic conditions. Among the cited conditions, alkaline and photolytic environments show a high capacity to promote degradation in the fluoroquinolone class. In fact, this compound class is unstable under photolytic conditions, i.e. fast degradation of these drugs occurs upon exposure to UV radiation (Burhenne, Ludwig, Spiteller, 1999; Sunderland et al., 2001; Torniainen, Askolin, Mattinen, 2007; Paim et al., 2010). This instability promotes the formation of degradation products and may cause photosensitivity dermatitis (allergic or non-allergic), cytotoxicity and genotoxicity (Shimoda, 1998; Tokura, 1998; Stahlmann, 1999; Paim et al., 2013).

Fluoroquinolones, however, present differences in their structure degradation when exposed to UV light and alkaline $\mathrm{pH}$ (Torniainen, Askolin, Mattinen, 2007; Paim et al., 2010; Babic', Periša, Škoric, 2013; Ahmad et al., 2013). Different pathways of degradation have been shown, as well as photochemistry reactions among the various compounds. This indicates the necessity of understanding the differences in reactivity among the fluoroquinolones.

Molecular modelling is a set of computational tools based on theoretical methods of calculation largely used in drug design to understand the molecular structure and physicochemical properties of compounds with biological or chemical interest (Carvalho et al., 2003). Thus, in silico calculations are able to provide information about the behavior of molecules under specific circumstances, which may elucidate, theoretically, the stability of the quinolone class under certain conditions. These methodologies may be used to explain the degradation of quinolone chemical structures and also to identify some aspects which may influence their molecular reactivity (Kieffer et al., 2010; Kleinman et al., 2015).

The aim of this study was to explain changes to the chemical structure of five quinolones, including norfloxacin, ciprofloxacin, enrofloxacin, danofloxacin and gemifloxacin, under the influence of alkaline medium and UV light, using computational tools. These data may be used to understand the stability of these chemical structures and also to help the study of new fluoroquinolones drugs design.

\section{MATERIAL AND METHODS}

All chemicals used were of analytical grade and all solvents were of chromatographic grade. Methanol, acetonitrile and triethylamine (TEA) were obtained from Merck ${ }^{\circledR}$ (Darmstadt, Germany), while phosphoric acid was acquired from Vetec ${ }^{\circledR}$ (Duque de Caxias-RS, Brazil). Purified water was prepared using a Milli-Q Plus ${ }^{\circledR}$ system (Bedford, USA). Standard reference danofloxacin, enrofloxacin, norfloxacin and ciprofloxacin hydrochloride with purity of $\geq 98 \%$ were obtained from Sigma-Aldrich (St. Louis, USA). Standard reference gemifloxacin mesylate $(99 \%)$ was acquired from Toronto Research Chemicals, Inc. (Toronto, Canada).

\section{Apparatus}

A Shimadzu liquid chromatograph (Kyoto, Japan) equipped with an LC-20AT pump, an SIL-20A auto sampler, a CTO-20A column oven, a SPD-20AT photodiode-array detector and LC Solution V. 1.24 SP1 manager system software was used. A Millipore ${ }^{\circledR}$ nylon filter $(13 \mathrm{~mm} \times 0.45 \mu \mathrm{m})$ was used to filter the samples before injection. Separation was performed by an Agilent Zorbax ${ }^{\circledR} \mathrm{C}-18$ reverse phase column $(250 \mathrm{~mm} \times 4.6 \mathrm{~mm}$ $\mathrm{x} 5 \mu \mathrm{m}$ ID). Photodegradation studies were carried out in a photostability UV chamber $(0.98 \mathrm{~cm} \times 0.24 \mathrm{~m} \times 0.25 \mathrm{~m}$ height) coated with mirrors and equipped with UV-A and UV-C lamps (Light Express ${ }^{\circledR}, 352 \mathrm{~nm}, 30 \mathrm{~W}$ and Ecolume $\mathrm{ZW}^{\circledR}, 254 \mathrm{~nm}, 30 \mathrm{~W}$, respectively).

\section{Chromatographic conditions}

Each standard reference was performed according to the United States Pharmacopeia (USP, 2009), using the reported or validated method with minor modifications, in which each mobile phase was filtered through a $0.45 \mu \mathrm{m}$ nylon filter and degassed in an ultrasonic bath before use and stored in a dark closed flask at $4{ }^{\circ} \mathrm{C}$. The chromatographic conditions are provided in Table I.

\section{Preparation of quinolone standards, alkaline and photolytic degradation study Alkaline degradation}

Ciprofloxacin hydrochloride, danofloxacin, enrofloxacin, gemifloxacin and norfloxacin were accurately weighed $(10 \mathrm{mg})$ and dissolved in a 100 $\mathrm{mL}$ volumetric flask with $0.1 \mathrm{~mol} \mathrm{~L}^{-1} \mathrm{NaOH}$, obtaining a concentration of $100 \mu \mathrm{g} \mathrm{mL}^{-1}$ for each drug. The solutions were filtered through a $0.45 \mu \mathrm{m}$ membrane filter. Subsequently, $1.0 \mathrm{~mL}$ of each solution was placed in a 10 $\mathrm{mL}$ volumetric flask and stored at room temperature (21$23^{\circ} \mathrm{C}$ ) in the dark for 1 or $3 \mathrm{~h}$. Then, these solutions were removed, neutralized with $0.1 \mathrm{~mol} \mathrm{~L}^{-1} \mathrm{HCl}$ and diluted with methanol to achieve a concentration of $15 \mu \mathrm{g} \mathrm{mL}^{-1}$. To zero time results was measured immediately after dilution and 
Evaluation of the influence of fluoroquinolone chemical structure on stability

TABLE I - Chromatography conditions for the analysis of the products of forced degradation tests

\begin{tabular}{|c|c|c|c|c|c|c|c|}
\hline $\begin{array}{l}\text { Standard } \\
\text { Reference }\end{array}$ & $\begin{array}{l}\text { Aqueous } \\
\text { solution } \\
\text { (A) }\end{array}$ & pH & $\begin{array}{l}\text { Organic } \\
\text { solution } \\
\text { (B) }\end{array}$ & $\begin{array}{l}\text { Proportion } \\
\text { (A:B) }\end{array}$ & $\begin{array}{c}\text { Flow } \\
(\mathrm{mL} / \mathrm{min})\end{array}$ & $\begin{array}{l}\text { Oven } \\
\left(T^{\circ} \mathrm{C}\right)\end{array}$ & $\begin{array}{l}\text { Wavelength } \\
\text { (nm) }\end{array}$ \\
\hline Ciprofloxacin & $\begin{array}{c}\mathrm{H}_{3} \mathrm{PO}_{4} 0.025 \mathrm{M} \\
\text { adjusted with } \\
\text { TEA }^{1} \\
\end{array}$ & 3 & $\begin{array}{l}\text { Acetonitrile: } \\
\mathrm{H}_{2} \mathrm{O}(80: 20)\end{array}$ & $87: 13$ & 1.5 & 30 & 278 \\
\hline Danofloxacin & $\begin{array}{l}\text { TEA } 0.3 \% \\
\text { adjusted with } \\
\text { formic acid }{ }^{2}\end{array}$ & 3 & $\begin{array}{l}\text { Acetonitrile: } \\
\mathrm{H}_{2} \mathrm{O}(80: 20)\end{array}$ & $75: 25$ & 1.0 & 30 & 283 \\
\hline Enrofloxacin & $\begin{array}{c}\mathrm{KH}_{2} \mathrm{PO}_{4} 0.04 \\
\mathrm{M} \text { with TEA } \\
0.3 \%{ }^{3} \\
\end{array}$ & 2.7 & $\begin{array}{l}\text { Acetonitrile: } \\
\mathrm{H}_{2} \mathrm{O}(80: 20)\end{array}$ & $76: 24$ & 1.0 & 30 & 278 \\
\hline Gemifloxacin & $\begin{array}{c}\text { TEA } 0.3 \% \\
\text { adjusted with } \\
\mathrm{H}_{3} \mathrm{PO}_{4}^{4} \\
\end{array}$ & 3 & $\begin{array}{l}\text { Acetonitrile: } \\
\mathrm{H}_{2} \mathrm{O}(80: 20)\end{array}$ & $72: 28$ & 1.5 & 25 & 272 \\
\hline Norfloxacin & $\begin{array}{c}\mathrm{H}_{2} \mathrm{O}: \mathrm{H}_{3} \mathrm{PO}_{4} \\
(1000: 1) \\
\text { adjusted with } \\
\text { TEA }^{1} \\
\end{array}$ & 2.5 & $\begin{array}{l}\text { Acetonitrile: } \\
\mathrm{H}_{2} \mathrm{O}(80: 20)\end{array}$ & $80: 20$ & 1.0 & 40 & 275 \\
\hline
\end{tabular}

${ }^{+}$TEA, triethylamine; $\mathrm{H}_{2} \mathrm{O}$, ultra-pure water; ${ }^{1}$ United States Pharmacopeia (USP 32); ${ }^{2}$ Liu et al., 2011; ${ }^{3}$ Method home validated; ${ }^{4}$ Paim et al., 2010.

they were considered $100 \%$. Results determined from all times were compared to each other.

\section{Photolytic degradation}

Ciprofloxacin hydrochloride, danofloxacin, enrofloxacin, gemifloxacin mesylate and norfloxacin were accurately weighed $(10 \mathrm{mg})$ and dissolved in a $100 \mathrm{~mL}$ volumetric flask with methanol, obtaining a concentration of $100 \mu \mathrm{g} \mathrm{mL}^{-1}$ for each drug. The solutions were filtered through a $0.45 \mu \mathrm{m}$ membrane filter. Subsequently, 1.5 $\mathrm{mL}$ of each solution was placed in a semi-micro UVcuvette, sealed with parafilm (American Co. Brand, USA) and immediately placed in the UV chamber for the photodegradation study for 5, 15 or 30 minutes (three replicates per period). After the photolytic degradation study, the cuvette solutions were placed to a $10 \mathrm{~mL}$ volumetric flask and diluted with methanol (to $15 \mu \mathrm{g}$ $\mathrm{mL}^{-1}$ ). Then, a $1 \mathrm{~mL}$ aliquot of the solution was placed in a vial and $20 \mu \mathrm{L}$ were injected into the chromatographic system. To zero time results was measured immediately after dilution and they were considered 100\%. Results determined from all times were compared to each other.

\section{Statistical analysis}

Data analysis was performed using GraphPad Prism
5 (GraphPad Software, La Jolla, USA). Two-way ANOVA was used to investigate the results of the photolytic degradation study and descriptive statistics are expressed as mean \pm standard deviation (SD). For better visualization of the results, the absolute area from the solution measured immediately after dilution was considered as $100 \%$ and it was compared to the results from 5, 15 and 30 minutes of treatment. The Bonferroni post-hoc test was used for multiple comparisons and a $p$ value $<0.05$ was considered statistically significant.

\section{Computational tools}

The computational analyses were performed using Spartan $08^{\circledR}$ version for Windows (Wavefunction, Inc., USA) and all initial structures were built using atoms and structural fragments from its molecular editor. Geometry optimization was performed in the gaseous phase using Density Functional Theory (DFT), and the Becke three-parameter hybrid (B3) associated with LeeYang-Parr (LYP) correlation functionals, i.e. the B3LYP method, with the $6.31 \mathrm{G}^{*}$ basis set. Maps of HOMO and LUMO energies and electrostatic potential (MEPs) were also calculated. The isosurface of MEPs was obtained at the van der Waals contact surface, which represents the potentials superimposed onto a surface of constant electron density $\left(0.002 \mathrm{e} / \mathrm{au}^{3}\right)$. The isoenergy contours 
were generated in the range of 35 to $60 \mathrm{kcal} \mathrm{mol}^{-1}$. The color intensity indicates more or less positive or negative electrostatic regions in the molecule. All color-coded surfaces obtained from these calculations provided a measure of the overall size of the molecular fragment and the location of positive, characterized by blue, and negative, indicated by green (less negative) and red (more intensely negative) electrostatic potentials. HOMO and LUMO isosurfaces were calculated at $0.0032 \mathrm{au}^{2}$. The constants used in these isosurface calculations were the default parameters in Spartan software.

\section{RESULTS AND DISCUSSION}

In general, quinolones shows fast degradation under photolytic conditions, demonstrating high susceptibility to drug degradation when exposed to UV radiation, as described in the literature (Burhenne, Ludwig, Spiteller, 1999; Sunderland et al., 2001; Torniainen, Askolin, Mattinen 2007; Paim et al., 2010). Alsante et al. (2007) suggested a degradation of 5-20\% for establishing a stability method, since intermediate degradation products should not interfere in drug analysis. Liquid chromatography procedures showed adequate resolution for all quinolones and degradation products generated by photolytic and alkaline degradation.

The alkaline stress conditions used in this work were set in accordance with Paim et al. (2013). In this procedure, only gemifloxacin showed degradation at 1 and 3 hours in the presence of $0.1 \mathrm{~mol} \mathrm{~L}^{-1} \mathrm{NaOH}$ among the five compounds evaluated. For norfloxacin, ciprofloxacin, danofloxacin and enrofloxacin, no significant degradation occurred in alkaline medium at 5 and 15 minutes (Table II). Similar results were found in the literature, despite the different conditions tested. Ciprofloxacin showed 2.9\% of degradation in $0.5 \mathrm{~mol} \mathrm{~L}-1 \mathrm{NaOH}$ at $50^{\circ} \mathrm{C}$ under reflux for $5 \mathrm{~h}$ (Vaghela, Rao, 2013) and no degradation was observed for danofloxacin and enrofloxacin when exposed to $0.1 \mathrm{~mol} \mathrm{~L}-1 \mathrm{NaOH}$ at $80^{\circ} \mathrm{C}$ for $24 \mathrm{~h}$ (Liu et al., 2011) and $5.0 \mathrm{~mol} \mathrm{~L}-1 \mathrm{NaOH}$ at $70{ }^{\circ} \mathrm{C}$ for $1 \mathrm{~h}$ (Chakravarthy, Sailaja, Kumar, 2015), respectively. Nevertheless, 18.9\% norfloxacin degradation was found when diluted in acetonitrile and degraded with $1.0 \mathrm{~mol} \mathrm{~L}^{-1} \mathrm{NaOH}$ at $70{ }^{\circ} \mathrm{C}$ for 11 days. A strong alkaline solution and a long period of time was required for this fluoroquinolone to achieve these degradation values.

TABLE II - Forced degradation study for fluoroquinolones using $0.1 \mathrm{~mol} \mathrm{~L}^{-1} \mathrm{NaOH}$ in room temperature $\left(21-23^{\circ} \mathrm{C}\right)$

\begin{tabular}{lcc}
\hline Fluoroquinolone & $\begin{array}{c}\mathbf{1} \text { hour (\%) } \\
\pm \text { RSD }\end{array}$ & $\begin{array}{c}\mathbf{3} \text { hours (\%) } \\
\pm \text { RSD }\end{array}$ \\
\hline Ciprofloxacin & $100.24 \pm 2.29$ & $98.17 \pm 0.22$ \\
Enrofloxacin & $100.55 \pm 1.28$ & $100.92 \pm 0.32$ \\
Danofloxacino & $101.07 \pm 0.49$ & $102.50 \pm 0.41$ \\
Gemifloxacin & $26.91 \pm 3.62$ & - \\
Norfloxacin & $101.10 \pm 0.54$ & $101.63 \pm 2.08$ \\
\hline
\end{tabular}

Fluoroquinolones show instability in the photolytic test as demonstrated for some compounds such as ciprofloxacin, danofloxacin, clinafloxacin, enrofloxacin, gemifloxacin, levofloxacin, norfloxacin, ofloxacin, sitafloxacin and sparfloxacin (Engler et al., 1998; Shimoda, 1998; Burhenne, Ludwig, Spiteller, 1999; Lovdahl, Priebe, 2000; Sunderland et al., 2001; Torniainen, Askolin, Mattinen, 2007; Paim et al., 2010; Babic', Periša, Škoric, 2013;). The results show relative stability under photolytic conditions for 5 minutes for ciprofloxacin, norfloxacin and enrofloxacin, while danofloxacin and gemifloxacin were unstable ( $>5 \%$ degradation). Ciprofloxacin and enrofloxacin underwent photodegradation after 15 minutes and norfloxacin remained stable under the influence of UV light within the time interval evaluated. In this regard, norfloxacin was considered the most stable drug among the tested fluoroquinolones (Table III).

Two-way ANOVA was performed to verify if there were significant differences among the fluoroquinolones

TABLE III - Degradation forced studies for fluoroquinolones using UVC radiation (254 nm)

\begin{tabular}{lccc}
\hline Fluoroquinolone & $\begin{array}{c}\mathbf{5} \text { minutes } \\
(\mathbf{\%}) \pm \text { RSD }\end{array}$ & $\begin{array}{c}\mathbf{1 5} \text { minutes } \\
(\mathbf{\%}) \pm \mathbf{R S D}\end{array}$ & $\begin{array}{c}\mathbf{3 0} \text { minutes } \\
\text { (\%) } \pm \text { RSD }\end{array}$ \\
\hline Ciprofloxacin & $95.8 \pm 1.34$ & $95.0 \pm 3.97$ & $93.5 \pm 3.80$ \\
Enrofloxacin & $96.8 \pm 1.03$ & $92.9 \pm 2.33$ & $91.5 \pm 1.91$ \\
Danofloxacin & $93.4 \pm 1.03$ & $92.3 \pm 0.28$ & $91.1 \pm 1.91$ \\
Gemifloxacin & $82.4 \pm 1.37$ & $49.7 \pm 0.78$ & $25.4 \pm 1.27$ \\
Norfloxacin & $97.8 \pm 1.33$ & $98.2 \pm 1.55$ & $99.5 \pm 2.44$ \\
\hline
\end{tabular}

Media \pm standard deviation are expressed in percentage. RSD, relative standard deviation 
relative to degradation by the action of UVC $254 \mathrm{~nm}$ light. According to the results, there were significant differences between gemifloxacin and the other fluoroquinolones at all time points tested $(\mathrm{p}<0.001)$.

Ciprofloxacin and enrofloxacin showed significant differences after 30 minutes of UV light exposure $(p<0.01)$ when compared to norfloxacin. Enrofloxacin also demonstrate in 15 minutes $(\mathrm{p}<0.01$ and $\mathrm{p}<0.001)$. Significant differences were showed by danofloxacin throughout the experiment when compared with norfloxacin ( 5 minutes, $\mathrm{p}<0.05 ; 15$ minutes, $\mathrm{p}<0.01 ; 30$ minutes, $\mathrm{p}<0.001)$. The results are shown in Figure 2.

Fluoroquinolone behavior in the photolytic assay (0-30 $\mathrm{min}$ ) demonstrated the absence of chromatographic coelution of impurities and/or degradation products from ciprofloxacin, enrofloxacin, danofloxacin, norfloxacin and gemifloxacin in the conditions tested. Peak purity tools showed the absence of impurities and/or degradation products from ciprofloxacin, enrofloxacin, danofloxacin, norfloxacin and gemifloxacin peaks in the photolytic assay. In fact, only gemifloxacin showed visible degradation products in the chromatogram under the tested conditions. These results are shown in Figure 3.

\section{Computational procedures}

The DFT method using the B3LYP functional and the $6.31 \mathrm{G}^{*}$ basis set was used to optimize the geometry of the chemical structures of the five fluoroquinolones in the gaseous phase. Chemical structures in space filling, tube and maps of energies of density of electrostatic potential (MEP), of HOMO and LUMO were generated in this step. The properties of $\mathrm{E}_{\text {Hомо }}, \mathrm{E}_{\mathrm{LUMO}}$ and GAP $\left(\mathrm{E}_{\mathrm{LUMO}^{-}}\right.$ $\mathrm{E}_{\text {номо }}$ ) were calculated and used to study the reactivity of fluoroquinolones. All structures, maps and physicochemical properties are shown in Figure 4 and Table IV.

The main structural differences among the five fluoroquinolones are the moieties attached at positions

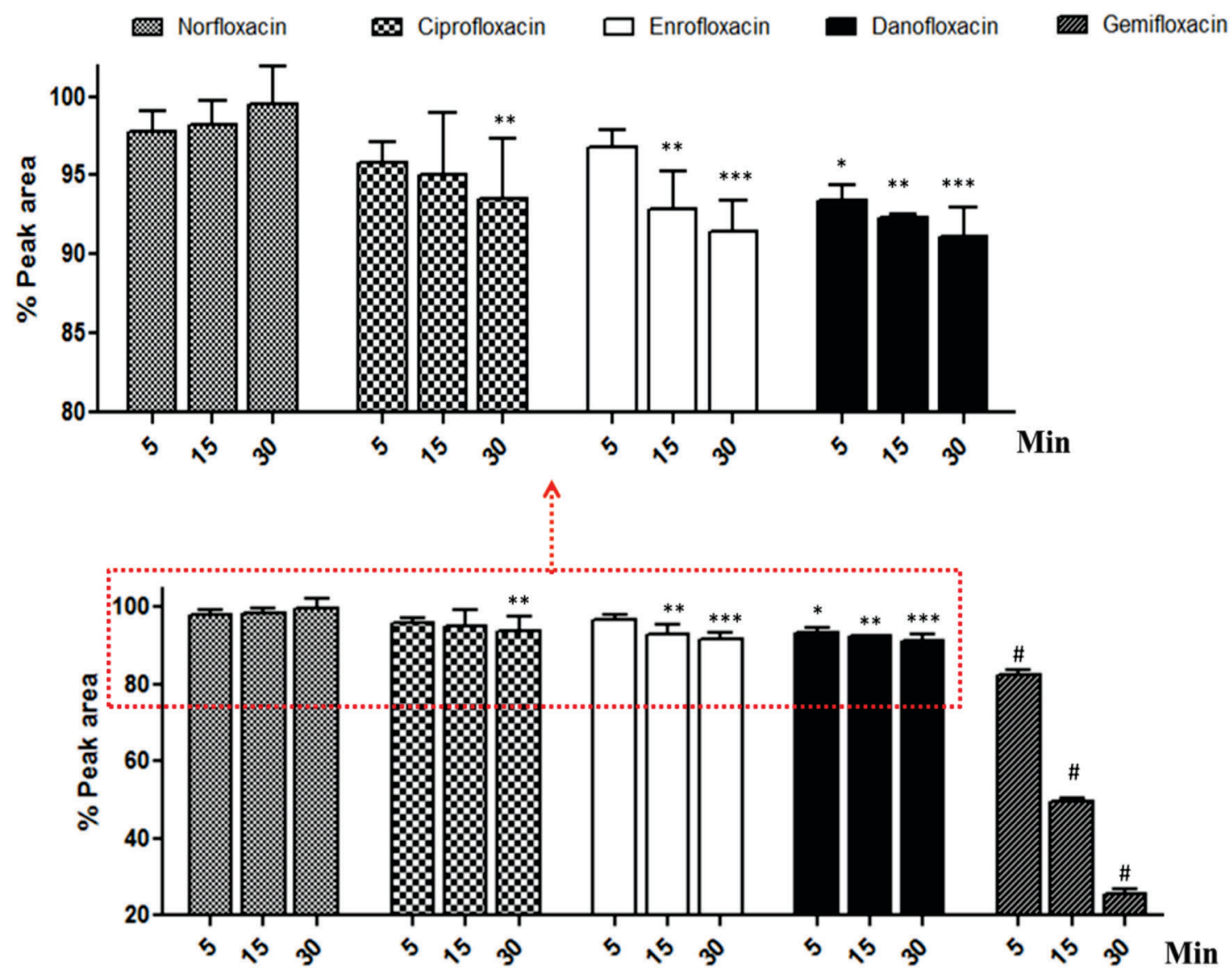

FIGURE 2 - Results of degradation of fluoroquinolones after UVC radiation under photolytic conditions (A) and expanded graphic to $100-75 \%$ peak axis area (B). Media and standard deviation are expressed in percentage. ${ }^{*}$ means statistical difference $\mathrm{p}$ $<0.05$ compared to norfloxacin; $* *$ means statistical difference $\mathrm{p}<0.01$ to norfloxacin; $* * *$ means statistical difference $\mathrm{p}<0.001$ to norfloxacin; " means statistical difference $\mathrm{p}<0.001$ between gemifloxacin compared to other fluoroquinolones. 

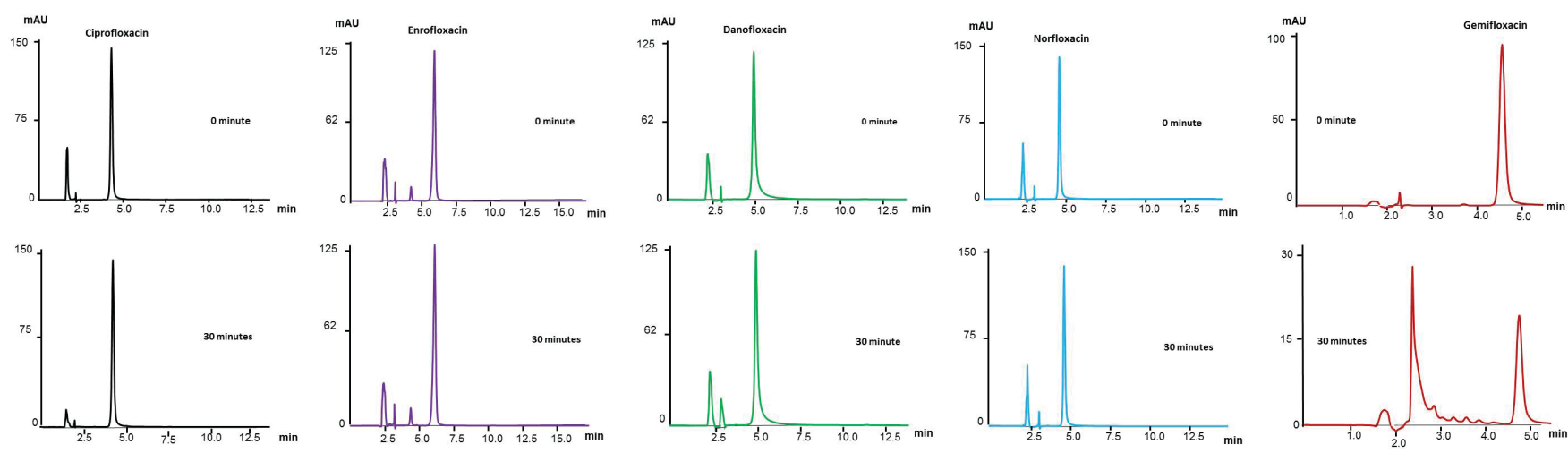

FIGURE 3 - Chromatograms of fluoroquinolones after treatment in photolytic conditions at time of 0 and 30 minutes. Chromatographic conditions describing in Table I.

1 and 7 of the quinolone ring, and the nitrogen atom at position 8 . Norfloxacin shows an ethyl moiety attached at position 1 in comparison to the other fluoroquinolones which present a cyclopropane ring attached at this position. The fluoroquinolones tube models showed a similar structure, in which the quinolone ring is not a coplanar structure with carboxylic acid and substituent groups are attached to positions 1 and 7 . In the space filling models, it is possible to observe that the lateral chain is higher according to gemifloxacin $>$ danofloxacin $>$ enroflox acin $>$ ciprofloxacin $\approx$ norfloxacin.

MEPs, HOMO and LUMO maps were generated in order to understand the mechanism of degradation of fluoroquinolone chemical structures, since these properties are generally associated with the reactivity and stability of compounds. Fluoroquinolone MEPs showed the electronegative value range around the molecules, but with high sites of this property in the carboxylic acid and the quinolone ring as well as the nitrogen atom of the piperazine ring. Sites of positive electrostatic charge were located in the hydrogen atom of carboxylic acid and at the ethyl or cyclopropane ring. The HOMO and LUMO energy sites are shown in Figure 4. HOMO sites were almost evenly distributed around the structures; however, gemifloxacin and ciprofloxacin showed lower sites in the ring attached at position 7 in comparison with enrofloxacin, danofloxacin and norfloxacin. LUMO sites were located mainly at the quinolone ring. No differences were observed among the fluoroquinolones studied.

\section{Evaluation of the influence of chemical structure on fluoroquinolone degradation}

Gemifloxacin was the most unstable compound under both alkaline and photolytic conditions when this molecule was compared with other fluoroquinolones.
The presence of a five member ring attached at position 7 and a nitrogen atom instead carbon located at position 8 of the quinolone ring may influence the reactivity of this molecule. In this sense, observing the MEPs, the nitrogen atom of the quinolone ring showed more negative electrostatic potential located at this position, which was different from the other fluoroquinolones.

In the alkaline forced stress test, ciprofloxacin, enrofloxacin, danofloxacin and norfloxacin showed a similar profile of degradation (Table II). Considering the maps and the calculated physicochemical properties, it was observed that gemifloxacin and ciprofloxacin showed lower $\mathrm{E}_{\text {номо }}$ sites in the rings attached at position 7. This property, however, appears to have no influence on the alkaline degradation of these compounds since ciprofloxacin did not undergo alkaline degradation. Gemifloxacin showed a higher value of $\mathrm{E}_{\text {LUMO }},-1.33$ $\mathrm{eV}$, in comparison with the other compounds, but this property, as well as the tube and space filling models and GAP energy, did not show characteristics which may help in understanding alkaline stability under the studied conditions.

In the photolytic degradation study, norfloxacin was the most stable compound compared to the other four fluoroquinolones (Figure 2). The presence of an ethyl moiety in relation to cyclopropane is the main difference and may suggest that the presence of a three membered ring promotes instability in the fluoroquinolone structure. This feature is in agreement with a study by Babic', Periša and, Škoric (2013), which demonstrated cyclopropane ring cleavage in enrofloxacin when submitted to photolytic conditions.

Danofloxacin and gemifloxacin were found to be the most unstable compounds after five minutes of the photolytic assay. Paim et al. (2016) performed a photolytic degradation study of gemifloxacin in which a product from 
<smiles>CCn1cc(C(=O)O)c(=O)c2cc(F)c(N3CCNCC3)cc21</smiles>

Norfloxacin

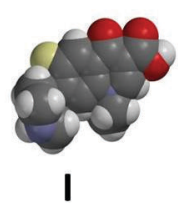

।

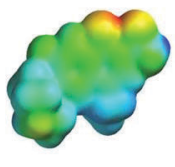

II
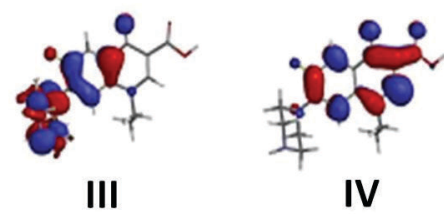

IV<smiles>O=C(O)c1cn(C2CC2)c2cc(N3CCNCC3)c(F)cc2c1=O</smiles>

Ciprofloxacin
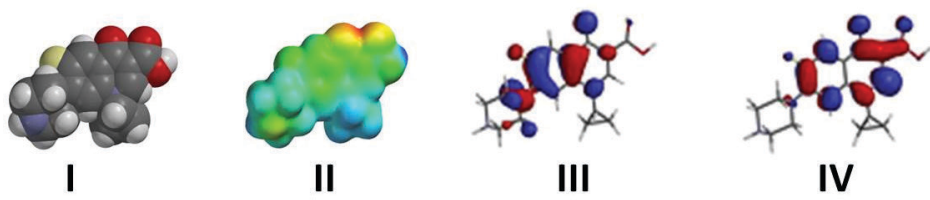<smiles>CCN1CCN(c2cc3c(cc2F)C(O)C(C(=O)O)=CN3C2CC2)CC1</smiles>

Enrofloxacin

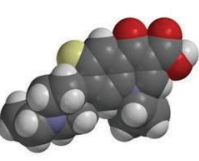

I

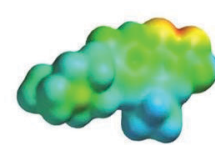

II

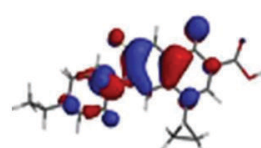

III

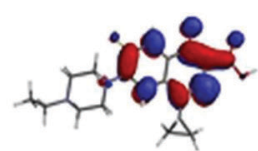

IV

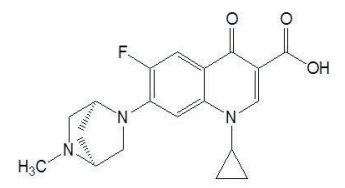

Danofloxacin

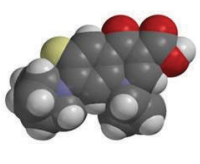

I

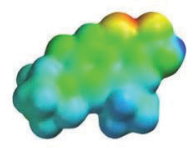

II

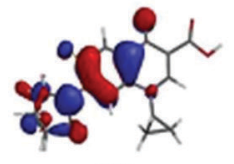

III

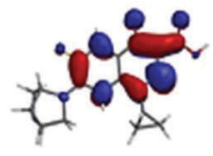

IV<smiles>CON=C1CN(C2N=C3C(=CC2F)C(O)C(C(=O)O)=CN3C2CC2)CC1CN</smiles>
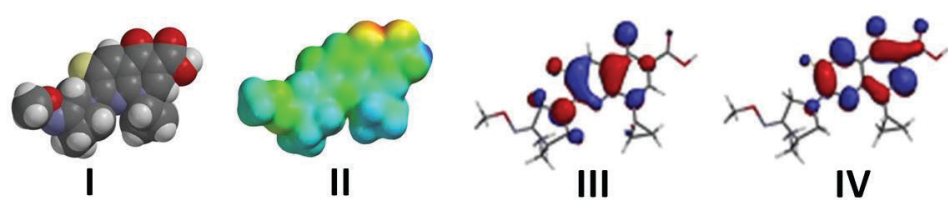

\section{Gemifloxacin}

FIGURE 4 - Chemical structure, space filing model, MEPs, maps of HOMO and LUMO energy 3D distribution of fluoroquinolones. I - Space filing model; II- MEPs; III - HOMO energy; IV - LUMO energy. MEPs 3D, tube and space filling models obtained from DFT/3BLYP-6.31G* calculations using Spartan'08 for Windons with isosurface $0.002 \mathrm{eV}$. Color range: -60.000 (red) to 35.000 (blue) $\mathrm{kcal} \mathrm{mol}^{-1}$.

TABLE IV - Energy of HOMO, LUMO and GAP eigenvalues obtained from DFT/3BLYP-6.31G* calculations using Spartan'08 for Windows

\begin{tabular}{lccc}
\hline Quinolone & $\mathbf{E}_{\text {номо }}(-) \mathbf{e V}$ & $\mathbf{E}_{\text {LUмо }}(-) \mathbf{e V}$ & $\mathbf{G A P}(-) \mathbf{e V}$ \\
\hline Ciprofloxacin & 5.70 & 1.20 & 4.50 \\
Enrofloxacin & 5.68 & 1.19 & 4.49 \\
Danofloxacin & 5.44 & 1.11 & 4.33 \\
Gemifloxacin & 5.67 & 1.33 & 4.34 \\
Norfloxacin & 5.46 & 1.22 & 4.24 \\
\hline
\end{tabular}


the original fluoroquinolone with a structure missing the ring attached to position 7 was isolated and identified. Danofloxacin has five and six member fused rings similar to the five member ring of gemifloxacin, which may explain the enhanced degradation observed in comparison with norfloxacin, ciprofloxacin and enrofloxacin. These three compounds have a piperazine ring attached to position 7 of the quinolone nucleus and which may make these molecules more stable under photolytic conditions. Babic', Periša, Škoric (2013) suggested the oxidative photodegradation of enrofloxacin and ciprofloxacin may occur at the piperazine ring attached at position 7 by opening the ring. In another study, Hubicka et al. (2014) identified sixteen degradation products of danofloxacin by LC-MS/MS when it was submitted to photolytic tests. All of them showed alterations mainly at the fused rings of the lateral chain. Additionally, Sturini et al. (2012) showed fluoroquinolone degradation under photocatalytic conditions using $\mathrm{TiO}_{2}$; they indicated five member rings may be more unstable than six member rings. These data confirm the influence of the substituent moieties attached at position 7 on the stability of fluoroquinolone structures.

Gemifloxacin presents a nitrogen atom on the quinolone ring with more negative electrostatic potential located at this position; this may indicate a more susceptible site for interactions with photolytic energy. Similar to alkaline conditions, the physicochemical properties such as $\mathrm{E}_{\text {Hомо }}, \mathrm{E}_{\mathrm{LUMO}}$ and GAP, the maps of the molecular orbitals (HOMO and LUMO), as well as the tube and space filling models do not show differences that explain the distinct photolytic degradation behavior under the studied conditions. It has been suggested to apply the concepts of Fukui indices or to determine bond dissociation enthalpies in order to predict the susceptibility of fluoroquinolone degradation in an alkaline or photolytic environment. These procedures may be important to understand the degradation process, but they are not within the scope of this study.

The differences in stability of the five studied fluoroquinolones should be considered because they provide an appropriate comparison among the drugs. Structural features of these compounds may be used in the design of effective and more stable fluoroquinolones. These results are also important since they may increase efficacy and establish the shelf life of the drug product.

\section{CONCLUSION}

These studies suggest greater instability of gemifloxacin in comparison with the other fluoroquinolones under all conditions evaluated. A photolytic environment causes degradation of this class of compound and they must be protected from UV light. Chemical structure of these compounds or, specifically, the moiety attached to the quinolone ring should be strongly considered according with the influence on stability. MEPs are an interesting tool for the description of fluoroquinolone reactivity and can be used to investigate degradation products in stress stability studies.

\section{ACKNOWLEDGEMENTS}

The authors declare there is no conflict of interest. This work has been supported by the CAPES (PNPD 2014), CNPq (Edital Universal Processo N ${ }^{\circ} 458355 / 2014$ 3), PDA-UNIPAMPA 2015.

\section{REFERENCES}

Ahmad I, Bano R, Sheraz MA, Ahmed S, Mirza T, Ansari SA. Photodegradation of levofloxacin in aqueous and organic solvents: a kinetic study. Acta Pharm. 2013;63(2):223-229.

Alsante KM, Ando A, Brown R, Ensing R, Hatajik TD, Kong W, Tsuda Y. The role of degradant profiling in active pharmaceutical ingredients and drug products. Adv Drug Deliv Rev. 2007;59(1):29-37.

Andersson MI, Macgowan AP. Development of the quinolones. J Antimic Chemoth. 2003;51(Suppl 1):1-11.

Babic' S, Periša M, Škoric' I. Photolytic degradation of norfloxacin, enrofloxacin and ciprofloxacin in various aqueous media. Chemosphere. 2013;91(11):1635-1642.

Brasil. Agência Nacional de Vigilância Sanitária. Anvisa. RDC $\mathrm{N}^{\circ}$ 58, de 20 de dezembro de 2013. [cited 2016 June 14]. Available at: http://bvsms.saude.gov.br/bvs/saudelegis/ anvisa/2013/rdc0058_20_12_2013.pdf.

Burhenne J, Ludwig M, Spiteller, M. Polar photodegradation products of quinolones determined by HPLC/MS/MS. Chemosphere. 1999;38(6):1279-1286.

Chakravarthy VA, Sailaja BBV, Kumar AP. Stability-indicating RP-HPLC method for simultaneous estimation of enrofloxacin and its degradation products in tablet dosage forms. J Anal Meth Chem. 2015;2015:735145.

Carvalho I, Pupo MT, Borges ADL, Bernardes LSC. Introdução à modelagem molecular de fármacos no curso experimental de química farmacêutica. Quim Nova 2003;26(3):428-438. 
Engler M, Rusing G, Sorgel F, Holzgrabe U. Defluorinated sparfloxacin as a new photoproduct identified by liquid chromatography coupled with UV detection and tandem mass spectrometry. Antimicrob Agents Chemother. 1998;42(5):11511159.

Hubicka U, Zuromska-Witek B, Zmudzki P, Stanisławski M, Krzek J. Determination of danofloxacin and its photodegradation products by HPLC-DAD. Kinetic evaluation of the degradation process and identification of photoproducts by mass spectrometry. Anal Methods. 2014;6:2490-2498.

International Conference on Harmonisation. ICH harmonized tripartite guidelines. Impurities in new drug products. 2006a. [cited 2016 June 14]. 16 p. (Q3B R2). Available at: https://www. ich.org/fileadmin/Public_Web_Site/ICH_Products/Guidelines/ Quality/Q3B_R2/Step4/Q3B_R2_Guideline.pdf.

International Conference on Harmonisation. ICH harmonized tripartite guidelines, Impurities in new drug substances, $2006 \mathrm{~b}$. [citado 2016 Jun 14]. 15 p. (Q3A R2). Available at: https://www. ich.org/fileadmin/Public_Web_Site/ICH_Products/Guidelines/ Quality/Q3A_R2/Step4/Q3A_R2_Guideline.pdf.

International Conference on Harmonisation. ICH guidelines. Stability testing of new drug substance and products, 2003. [cited 2016 June 14]. 24 p. (Q1A R2). Available at: https://www. ich.org/fileadmin/Public_Web_Site/ICH_Products/Guidelines/ Quality/Q1A_R2/Step4/Q1A_R2_Guideline.pdf

Kieffer J, Bremond E, Lienard P, Boccardi G. In silico assessment of drug substances chemical stability. J Mol Struc Theochem. 2010;954(1-3):75-79.

Kleinman MH, Elder D, Teasdale A, Mowery MD, Mckeown AP, Baertschi SW. Strategies to address mutagenic impurities derived from degradation in drug substances and drug products. Org Proc Res Develop. 2015;19(11):1447-1457.

Klick S, Muijselaar PG, Waterval J, Eichinger T, Korn C, Gerding TK, Debets AJ, De Griend CS, Somsen GW, De Jong GJ. Towards a generic approach for stress testing of drug substances and drug products. Pharm Technol. 2005;29:48-66.

Liu ZY, Zhou XX, Zhang HH, Wan L, Sun ZL. An integrated method for degradation products detection and characterization using hybrid ion trap/time-of-lightmass spectrometry and data processing techniques: Application to study of the degradation products of danofloxacin under stressed conditions. Anal Bioanal Chem. 2001;399(7):2475-2486.
Lovdahl MJ, Priebe SR. Characterization of clinafloxacin photodegradation products by LCMS: MS and NMR. J Pharm Biom Anal. 2000;23(2-3):521-534.

Paim CS, Fuhr F, Martins MT, Gnoatto S, Bajerski L, Garcia CV, Steppe M, Schapoval EES. Structural elucidation of gemifloxacin mesylate degradation product. Biomed Chromatog. 2016;30(3):459-465.

Paim CS, Fuhr F, Miron DS, Pereira RL, Malesuik MD, Steppe M, Schapoval EES. Stability-indicating lc assay and determination of system suitability limits with a robustness test of gemifloxacin mesylate in tablets. Curr Anal Chem. 2010;6(4):269-276.

Paim CS, Nogueira DR, Mitjans M, Lopez DR, Perez JL, Steppe M, Schapoval EES, Vinardell MP. Biological safety studies of gemifloxacin mesylate and related substances. Photochem Photobiol Anal. 2013;12(5):805-812.

Petri WA. Antimicrobianos: Sulfonamidas, sulfametoxazol, trimetoprim, quinolonas e agentes para infeccoes do trato urinário. In: Hardman, JG, Limbird LE, Goodman AG, (editores). Goodman \& Gilman - As bases farmacologicas da terapêutica. 10 ed. Porto Alegra: McGraw-Hill Interamericana do Brasil; 2005, p. 877-890.

Shimoda K. Mechanisms of quinolone phototoxicity. Toxic Lett. 1998;102/103:369-373.

Silva KER, Alves LDS, Soares MFR, Passos RCS, Faria AR, Neto PJR. Modelos de avaliação da estabilidade de fármacos e medicamentos para a indústria farmacêutica. Rev Cienc Farm Básica Apl. 2009;30(2):129-135.

Singh R, Junwal M, Modhe G, Tiwari H, Kurmi M, Parashar N, Sidduri P. Forced degradation studies to assess the stability of drugs and products. Trends Anal Chem. 2013;49:71-88.

Stahlmann R, Lode H. Toxicity of quinolones. Drugs. 1999;58(Suppl 2):37-42.

Sturini M, Speltini A, Maraschi F, Profumo A, Pretali L, Irastorza EA, Fasani E, Albini A. Photolytic and photocatalytic degradation of fluoroquinolones in untreated river water under natural sunlight. Appl Catal B. 2012;119/120:32-39. 
Sunderland J, Tobin CM, Hedges AJ, Macgowan AP, White LO. Antimicrobial activity of fluoroquinolone photodegradation products determined by pararell-line bioassay and high performance liquid chromatography. J Antimicrob Chem. 2001;47(3):271-275.

Tokura Y. Quinolone photoallergy: Photosensitivity dermatitis induced by systemic administration of photohaptenic drugs. J Dermatol Sci. 1998;18(1):1-10.

Torniainen K, Askolin CP, Mattinen J. Isolation and structure elucidation of an intermediate in the photodegradation of ciprofloxacin. J Pharm Biom Anal. 1997;16(3):439-455.
The United States Pharmacopoeia. USP. USP 32, NF 27. 32th ed. Rockville: United States Pharmacopeial Convention; 2009.

Vaghela BK, Rao SS. A novel validated stability indicating high performance liquid chromatographic method for estimation of degradation behavior of ciprofloxacin and tinidazole in solid oral dosage. J Pharm Bioallied Sci. 2013;5(4):298-308.

Received for publication on $09^{\text {th }}$ November 2016 Accepted for publication on $27^{\text {th }}$ September 2017 